\title{
Recruitment and participant baseline characteristics in the dialysis outcomes in those aged 65 years or older study
}

Bronwen McNoe ${ }^{1}$, John B. W. Schollum², Sarah Derrett ${ }^{1}$, Mark R. Marshall ${ }^{3}$, Andrew Henderson ${ }^{4}$, Ari Samaranayaka ${ }^{5}$ and Robert J. Walker ${ }^{2^{*}}$ (D)

\begin{abstract}
Background: Despite an increasing number of older people commencing dialysis the impact of dialysis on their quality of life and survival, remains unclear. The Dialysis Outcomes in those aged over 65 years or older study is an accelerated prospective cohort longitudinal design study, designed to obtain sufficient health related quality of life data, linked to clinical data, to inform clinicians' and patients' decision-making with respect to end stage kidney disease (ESKD), outcomes, and options for management in New Zealand (NZ).

Methods: The study has an accelerated prospective cohort longitudinal design, comprised of cross-sectional and longitudinal components. We report the baseline data on the 225 participants enrolled in the study. Dialysis duration was grouped in tertiles from less than one year (incident patients), 1-3 years and greater than 3 years. Health related quality of life data was obtained from self-reported questionnaires including KDQoL-36, EQ-5D-3 L, FACIT, WHODAS II, and the Personal Well-being Score.

Results: The median age of the cohort was 71 years and two thirds were male. Three quarters of the participants were on dialysis at the baseline, with $42 \%$ of those on home dialysis (haemodialysis or peritoneal dialysis). Māori and Pacific people were over represented (20\% Māori and 24\% Pacific) in the sample, when compared to the general NZ population of the same age group (where 5\% are Māori and 2\% are Pacific). At baseline, there were no differences observed in sociodemographic, quality of life or health characteristics between the dialysis groups either by modality or duration of dialysis.

Conclusions: We report the baseline characteristics of participants enrolled prospectively into a longitudinal cohort observational study examining health related quality of life factors with clinical characteristics on dialysis outcomes in a group of New Zealanders aged 65 years or older who are either on dialysis or have been educated about dialysis (BMC Nephrol 14:175, 2013). Subsequent publications are planned, analysing the prospective longitudinal data to identify key factors that determine both outcome and quality of life for individuals of this age group.
\end{abstract}

Trial registration: ACTRN12611000024943.

Keywords: Dialysis, Elderly, Quality of life, Comorbidities

\footnotetext{
* Correspondence: rob.walker@otago.ac.nz

${ }^{2}$ Department of Medicine, University of Otago, Dunedin, New Zealand

Full list of author information is available at the end of the article
}

(c) The Author(s). 2019 Open Access This article is distributed under the terms of the Creative Commons Attribution 4.0 International License (http://creativecommons.org/licenses/by/4.0/), which permits unrestricted use, distribution, and reproduction in any medium, provided you give appropriate credit to the original author(s) and the source, provide a link to the Creative Commons license, and indicate if changes were made. The Creative Commons Public Domain Dedication waiver (http://creativecommons.org/publicdomain/zero/1.0/) applies to the data made available in this article, unless otherwise stated. 


\section{Background}

Over the past two decades there has been a considerable increase in the proportion of older patients commencing dialysis; yet there is some uncertainty about the outcome of dialysis in this population with respect to survival and also patients' health-related quality of life (HRQoL). There is currently minimal prospective data published on the key factors that might influence decision making or outcomes in the older age groups commencing renal replacement therapy. More recently, the SONG (Standardised Outcomes in NephroloGy) initiative has identified the importance of patient-reported outcome measures in studies of patients on dialysis [1]. It is therefore important to identify those factors to inform shared decision making.

The Dialysis Outcomes in those aged 65 years or older study (DOS65) is an accelerated prospective cohort longitudinal study, designed to obtain sufficient HRQoL data, linked to clinical data, to inform clinicians' and patients' decision-making with respect to end stage kidney disease (ESKD) outcomes and options for management in New Zealand (NZ) [2]. This study commenced in January 2010 and final follow up was completed in June 2016.

The focus of this paper is to describe the key characteristics of the study cohort at baseline, including the patients' health status, their treatment modality (not on dialysis, haemodialysis or peritoneal dialysis) and location of treatment (i.e. home or clinic/hospital facility). From the cross-sectional data at baseline, we hypothesise that HRQoL differs between patients according to: sex, ethnicity, comorbidities, type of dialysis treatment, health service satisfaction, and duration of dialysis.

\section{Methods}

\section{Study design}

The study has an accelerated prospective cohort longitudinal design, comprised of cross-sectional and longitudinal components (Fig. 1). The methods have been described previously [2]. In particular, individuals who had a very limited life expectancy or significant active co-morbidity which was affecting their health were excluded by principal investigator at each site, as this would clearly impact on the perceived HRQoL questionnaires, but may not be attributable to dialysis and ESKD specifically. Recruitment was targeted to try and get at least one set of interviews at 12 months after enrolment for all participants where possible.

\section{Setting and participants}

Eligible patients resided in one of three District Health Board (DHB) regions within NZ (Counties Manukau, Hawkes Bay or Southern) which reflect the diversity of the New Zealand population with Counties Manukau, a large urban population with high representation of Māori and Pacific people; Hawkes Bay, a regional farming centre which also has a high proportion of Mãori and the Southern region with a predominantly European population spread over a large demographic area. All participants were 65 years or older, their clinical team considered them well enough to be approached to participate, and were either established on dialysis at the baseline interview or had a eGFR $15 \mathrm{ml} / \mathrm{min} 1.73 \mathrm{~m}^{2}$ or less and had commenced pre-dialysis education. In practice, this meant that some

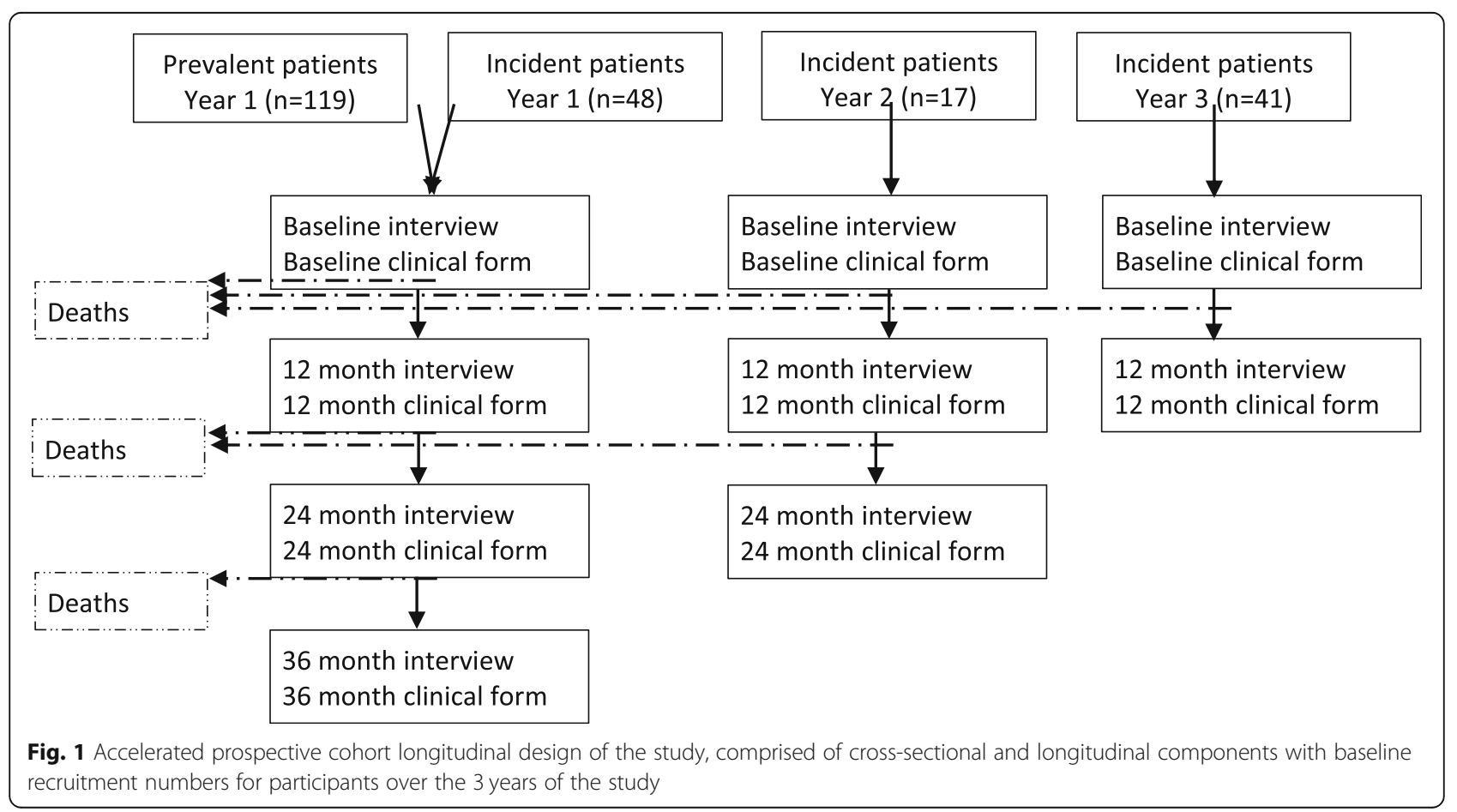


patients were already on dialysis for a number of years at the time of recruitment, whereas other patients had just commenced treatment. Clinicians from each DHB approached eligible patients and invited them to participate in the study. Ethical approval was granted by the New Zealand Health and Disability Ethics Committee (MEC/10/08/ 084) and the study is registered with Australian and New Zealand Clinical Trials Registry (ACTRN12611000024943).

\section{Data collection}

Following consent, the patients were telephoned by a trained interviewer to arrange an interview either face to face or by telephone depending on the participants' preference. Interview questions were read aloud to participants, who were also provided with a printed sheet of response options to facilitate the interviews. The baseline interview was predominantly comprised of structured closed-response questions (see below).

Clinical data was collected at the same time as the first (baseline) interview for each participant. Clinicians completed a standardised clinical data abstraction form based on report forms used for the Dialysis Outcomes and Practice Patterns Study. Data collected included ethnicity, age, sex, co-morbidities, laboratory data, anthropometric measures, prescribed medications and details of renal replacement therapy [3] In addition, we obtained aggregate data from routinely collected clinical and administrative hospital datasets included in the Australian and New Zealand Dialysis and Transplantation Registry (ANZDATA) to compare characteristics of our cohort with the broader New Zealand wide dialysis population in this age group [4].

\section{Variables}

We collected socio-demographic characteristics using the same questions used in the 2009 New Zealand census: sex, age, relationship status, occupation, living arrangements and self-reported ethnicity [5]. As participants were able to select multiple ethnicities, ethnicity was prioritised into Māori (New Zealand's indigenous population), Pacific peoples (Samoan, Tongan, Fijian, Cook Islander), other ethnicities (e.g. other European, Chinese, Indian) or New Zealand European $[5,6]$. Socioeconomic data included home ownership [5], whether income was solely dependent on Government Superannuation [7], use of a means-tested community services card (to provide additional subsided health care) [8], self-reported standard of living (responses: high, fairly high, medium, fairly low, low) [9], adequacy of household income to meet every day needs (not enough, just enough, enough or more than enough), and education (the responses were merged into 3 categories: none, secondary (age 12-18 years), post-secondary) [9].

The New Zealand Deprivation Index (NZDep2006) is calculated for small New Zealand geographical areas using 9 dimensions of socio-economic disadvantage to create a summary score to estimate socioeconomic status using data collected in Statistics New Zealand's 2006 Census of Population and Dwellings [10]. The higher the number (range 1-10) the greater the estimated socioeconomic deprivation.

General health status was assessed using the EQ-5D-3 L [11], as previously used in studies of Chronic Kidney Disease (CKD) populations [11, 12]. The Kidney Disease Quality of Life - 36 (KDQoL-36) was used to assess the functioning and well-being of people with CKD [12-14].

We collected responses to the Functional Assessment of Chronic Illness Therapy (FACIT) survey, which is a collection of health-related quality of life measures targeted to the management of chronic disease and has been validated in elderly populations [15]. The higher the score the higher the level of satisfaction with health care. A total FACIT score was calculated as a simple (unweighted) sum of all the subscale scores, rescaled to a 0 to 100 scale. This was calculated only for people with valid sub-scales for all dimensions.

The level of disability for participants was measured using the WHODAS II 12-item measure which assesses activity limitations and participation over the past 30 days using a five point Likert scale ("none/mild/moderate/extreme/cannot do") for each item. [16] A WHODAS disability score was derived using the summed approach (where $0=$ no disability and $48=$ disability). When one WHODAS item was missing, the individual's average was imputed; when more items were missing, the disability score was not derived. [16]

Well-being was measured using the Personal Wellbeing Index [17]. This scale is an eight-item measure assessing the level of satisfaction with; standard of living, health, achieving in life, relationships, safety, community connectedness, future security and spirituality or religion. Respondents rated their satisfaction on an 11 point scale (0 completely dissatisfied to 10 completely satisfied). Scores for individuals were derived as an average across all items and converted to a zero to 100 scale.

\section{Data analysis}

Data analysis was conducted Stata ${ }^{\circ} 13.1$ software (StataCorp. 2013. Stata Statistical Software: Release 13. College Station, TX, USA. Descriptive statistics were calculated. ANOVA (for continuous data) and Chi Square (for categorical data) were used to compare groups (e.g. non-responders versus responders).

\section{Results}

\section{Participants}

Between 1 January 2010 and 31 March 2014 there were 388 potential participants of whom 56 were ineligible for the first interview because; they died before interview was scheduled $(n=11)$ or a clinician advised interview would be inappropriate given the poor health status of the patient or anticipated limited life expectancy $(n=$ 
45). Of the 332 potential participants, 107 (32\%) declined to participate in the study, leaving 225 (68\%) participants (Figs. 1 \& 2). The demographic characteristics of patients who agreed and declined to participate in the study is provided in Table 1 . There were a number of statistically significant differences between the two groups. Participants were more likely to be male, of European ethnicity and on dialysis. Over half of the 225 participants (54\%) completed a face to face interview, $45 \%$ by telephone and 1 completed a postal questionnaire. Interviews took on average one hour to complete. 25 participants (11\%) had limited or no English language ability and were assisted by a bi-lingual translator.

A comparison of DOS65's population with the entire comparative age group on dialysis in NZ [4], found there was no significant difference in the distribution according to age or sex. In DOS65, $42 \%$ were dialysing at home which reflects national trends [4]. When compared to the New Zealand wide dialysis population of the same age [4], DOS65 had a higher proportion of Pacific participants ( $23 \%$ vs $17 \%)$, a similar proportion of Māori participants (22\% vs $25 \%)$ and a slightly lower proportion of New Zealand Europeans (43\% vs 49\%). When compared to the general NZ population over the age of 65, Mãori ( $22 \%$ vs $5 \%)$ and Pacific people ( $23 \%$ vs $2 \%$ ) were over represented in the study population [9].

Participant characteristics are summarised in Table 1. Nearly two thirds of the study cohort were male and the median age at interview was 71 years (interquartile range, IQR 68 to 76 years). Three quarters $(n=169)$ of the patients were receiving dialysis (109 haemodialysis and 60 peritoneal dialysis). Of those on dialysis, 70 (41\%) were dialysing at home; and 99 (59\%) underwent centre-based haemodialysis. 119 (70\%) had been dialysing for more than one year at baseline; 57 (34\%) had been dialysing for between 1 and 3 years and 62 (37\%) had been dialysing for more than 3 years. Fifty (30\%) were incident dialysis patients (started dialysis within the past 12 months). Of the 56 non-dialysis patients, 9 had elected for conservative treatment (i.e. had made a conscious choice to not go onto dialysis), and 47 were defined as pre-dialysis. There was no sub-cohort effect observed across dialysis duration (Table 2). Of the pre-dialysis patients, 5 had been deemed medically unfit to start dialysis, 41 had chosen to dialyse but had not reached the point at which dialysis needed to be started, and 1 patient had not yet made up his/her mind about whether to dialyse or not.

Diabetes mellitus was the most common cause of ESKD (41\%) followed by glomerulonephritis (17\%) and hypertensive disease (17\%). The majority of participants had 3 or more comorbidities, of which cardiovascular disease (CVD) (67\%), followed by diabetes mellitus (53\%) were the most common. The number of comorbidities ranged from zero to 6 with a median of 3 (IQR 2 to 4) (Table 1). Over half the population had previously smoked (52\%) though there were very few current smokers (6\%). The population was less well educated than the general NZ population of the same age with $48 \%$ of the study population not having achieved a secondary school education as compared with $39 \%$ of the NZ population over the age of 65 (2013 NZ Census). The study population lived in more deprived areas than the general NZ population over the age of 65 . DOS65 participants were poorer socioeconomically, according to the NZDep, than the general population (6.9 and 5.4 respectively, $p<0.01)$, and more than half $(54 \%)$ lived in areas classified as having the poorest three deciles. (Personal communication Dr. June Atkinson Department of Public Health, University of Otago Wellington, NZ; data sourced from Statistics New Zealand).

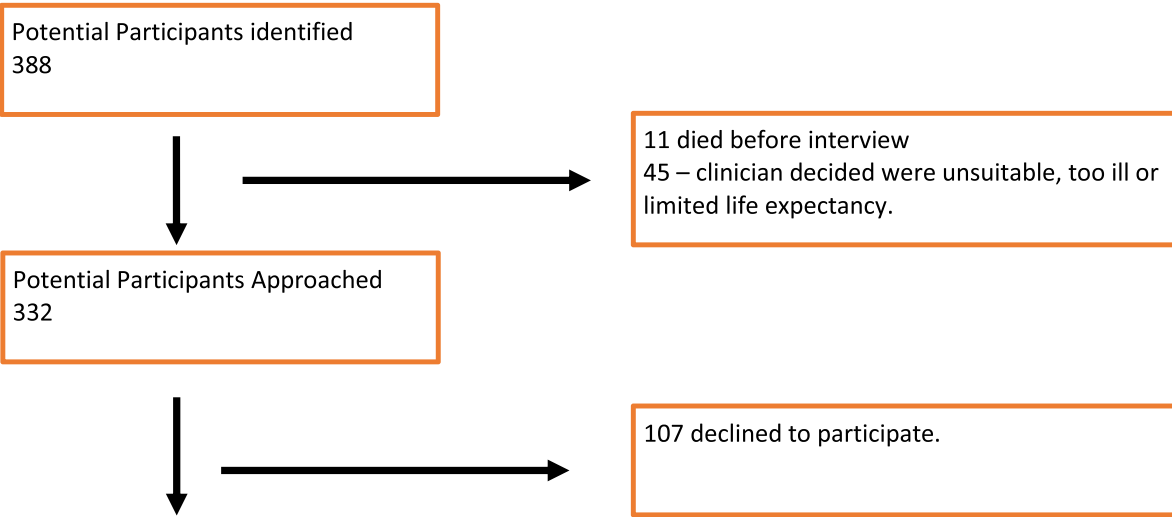

225 participants recruited

Fig. 2 Flow-chart demonstrating recruitment for the study 
Table 1 Comparison of participants and non-participants

\begin{tabular}{llll}
\hline & $\begin{array}{l}\text { Participated } \\
\text { Declined to }\end{array}$ \\
$\frac{(N=225)}{n} \%$ & $\frac{\text { participate }(N=107)}{n} p$ value
\end{tabular}

\begin{tabular}{llllll}
\hline Gender & & & & & \\
Male & 144 & 64.0 & 49 & 45.8 & \\
Female & 81 & 36.0 & 58 & 54.2 & 0.002
\end{tabular}

Age group

$\begin{array}{lllll}65-69 & 87 & 38.7 & 50 & 46.7 \\ 70-74 & 64 & 28.4 & 36 & 33.6 \\ 75-79 & 45 & 20.0 & 12 & 11.2 \\ 80+ & 29 & 12.9 & 9 & 8.4 \\ \text { median age } & 71 & - & 70 & -\end{array}$

Ethnicity (as in ANZDATA)

$\begin{array}{lllll}\text { European } & 108 & 48.0 & 11 & 10.3 \\ \text { Māori } & 45 & 20.0 & 24 & 22.4 \\ \text { Pacific } & 53 & 23.6 & 52 & 48.6 \\ \text { Other } & 19 & 8.4 & 19 & 17.8 \\ \text { Missing } & 0 & 0.0 & 1 & 0.9\end{array}$

Ethnicity (Self reported multiple ethnicities were prioritised)

$\begin{array}{lll}\text { Europeans } & 96 & 42.7 \\ \text { Māori } & 50 & 22.2 \\ \text { Pacific } & 52 & 23.1 \\ \text { Other } & 27 & 12.0\end{array}$

Receiving dialysis

Yes

No

$\begin{array}{llll}169 & 75.1 \quad 68 & 63.6\end{array}$

$\begin{array}{llll}56 & 24.9 & 39 & 36.4\end{array}$

Living Arrangement

$\begin{array}{lll}\text { Alone } & 33 & 14.7 \\ \text { Living with others } & 192 & 85.3\end{array}$

Cigarette smoking

$\begin{array}{lll}\text { Current smoker } & 14 & 6.2 \\ \text { Ex smoker } & 118 & 52.4 \\ \text { Never smoker } & 91 & 40.4 \\ \text { Missing } & 2 & 0.9\end{array}$

Missing

20.9

Alcohol drinker

Current drinker

$96 \quad 42.7$

Non drinker

$129 \quad 57.3$

Highest educational qualification

$\begin{array}{lll}\text { None } & 108 & 48.0 \\ \text { Secondary (age 13-18) } & 44 & 19.6 \\ \text { Post secondary } & 69 & 30.7 \\ \text { Missing } & 4 & 1.8\end{array}$

Comorbidities $^{\text {a }}$

$\begin{array}{lllll}\text { Cardiovascular disease } & 151 & 67.1 & 68 & 63.6\end{array}$

$\begin{array}{lllll}\text { Cerebrovascular disease } & 17 & 7.6 & 4 & 3.7\end{array}$
Table 1 Comparison of participants and non-participants (Continued)

\begin{tabular}{|c|c|c|c|c|c|}
\hline & \multicolumn{2}{|c|}{$\begin{array}{l}\text { Participated } \\
(N=225)\end{array}$} & \multicolumn{2}{|c|}{$\begin{array}{l}\text { Declined to } \\
\text { participate }(N=107)\end{array}$} & \multirow[t]{2}{*}{$\begin{array}{l}c h i^{2} \\
p \text { value }\end{array}$} \\
\hline & $\mathrm{n}$ & $\%$ & $n$ & $\%$ & \\
\hline $\begin{array}{l}\text { Peripheral vascular } \\
\text { disease }\end{array}$ & 45 & 20.0 & 21 & 19.6 & 0.94 \\
\hline Diabetes mellitus & 120 & 53.3 & 80 & 74.8 & $<0.01$ \\
\hline Respiratory disease & 49 & 21.8 & 12 & 11.2 & 0.02 \\
\hline $\begin{array}{l}\text { Cancer (other than skin } \\
\text { cancer) }\end{array}$ & 38 & 16.9 & 8 & 7.5 & 0.02 \\
\hline Musculoskeletal & 68 & 30.2 & 32 & 29.9 & 0.95 \\
\hline Other & 140 & 62.2 & 81 & 75.7 & 0.02 \\
\hline \multicolumn{6}{|l|}{ Comorbidity count } \\
\hline 0 to 2 & 104 & 46.2 & 40 & 37.4 & \\
\hline 3 to 6 & 121 & 53.8 & 67 & 62.6 & 0.13 \\
\hline \multicolumn{6}{|l|}{ Cause of ESKD } \\
\hline Glomerulonephritis & 38 & 16.9 & 15 & 14.0 & \\
\hline Hypertension & 38 & 16.9 & 10 & 9.3 & \\
\hline Polycystic kidney & 12 & 5.3 & 0 & 0.0 & $<0.01$ \\
\hline Diabetes mellitus & 92 & 40.9 & 68 & 63.6 & \\
\hline Other & 45 & 20.0 & 14 & 13.1 & \\
\hline
\end{tabular}

Table 3 describes participants' sociodemographic characteristics by baseline renal replacement therapy, dialysis duration and location of treatment. The length of time on dialysis (dialysis vintage) did not vary by gender, age, ethnicity, distance from dialysis facility or any makers of socioeconomic status. In contrast dialysis modality and location was highly associated with socio-demographic factors. Female participants were less likely to dialyse at home than males (27 vs 49\%). When compared to the NZ European population a smaller proportion of Māori (25 vs 61\%) or Pacific people (24vs 61\%) dialysed at home. Participants living further away from the dialysis centre were more likely to undertake a home therapy, particularly peritoneal dialysis. Patients dialysing in-centre (compared to those dialysing at home), were more likely to be socioeconomically disadvantaged as indicated by not owning their own home (72 vs $48 \%$ ), being more likely to have a community services card (85\%vs $62 \%)$, reporting a low/very low standard of living (14\% vs $3 \%$ ) and living in a more deprived NZDep area (mean 7.6 vs 6.1). Age had no impact on dialysis location and people living alone were no less likely to undertake a home therapy. Patients dialysing at home had a similar number of comorbidities to those dialysing in-centre. The characteristics of the pre-dialysis population was similar to the population on peritoneal dialysis. Females, Māori and Pacific people, those who lived closer to a dialysis centre, and those who were socioeconomically poorer, were more 
Table 2 Assessing possibility of subcohort effect in accelerated prospective design

\begin{tabular}{|c|c|c|c|c|c|c|c|c|c|}
\hline & \multicolumn{2}{|c|}{$\begin{array}{l}\text { Predialysis } \\
(n=56)\end{array}$} & \multicolumn{2}{|c|}{$\begin{array}{l}\text { Incident } \\
(<1 \text { year })(n=50)\end{array}$} & \multicolumn{2}{|c|}{$\begin{array}{l}\text { Prevalent } \\
(1-3 \text { years })(n=57)\end{array}$} & \multicolumn{2}{|c|}{$\begin{array}{l}\text { Prevalent } \\
(>3 \text { years })(n=62)\end{array}$} & \multirow[t]{2}{*}{$p$ value } \\
\hline & $\mathrm{n}$ & $\%$ & $\mathrm{n}$ & $\%$ & $\mathrm{n}$ & $\%$ & $n$ & $\%$ & \\
\hline \multicolumn{10}{|l|}{ Gender } \\
\hline Male & 37 & 66.1 & 33 & 66.0 & 35 & 61.4 & 39 & 62.9 & \\
\hline Female & 19 & 33.9 & 17 & 34.0 & 22 & 38.6 & 23 & 37.1 & 0.94 \\
\hline \multicolumn{10}{|l|}{ Age group } \\
\hline $65-69$ & 20 & 35.7 & 20 & 40.0 & 21 & 36.8 & 26 & 41.9 & \\
\hline $70-74$ & 11 & 19.6 & 16 & 32.0 & 15 & 26.3 & 22 & 35.5 & \\
\hline $75-79$ & 13 & 23.2 & 6 & 12.0 & 16 & 28.1 & 10 & 16.1 & 0.13 \\
\hline $80+$ & 12 & 21.4 & 8 & 16.0 & 5 & 8.8 & 4 & 6.5 & \\
\hline \multicolumn{10}{|l|}{ Ethnicity (self reported) } \\
\hline European & 30 & 53.6 & 19 & 38.0 & 23 & 40.4 & 24 & 38.7 & \\
\hline Māori & 10 & 17.9 & 10 & 20.0 & 18 & 31.6 & 12 & 19.4 & \\
\hline Pacific & 6 & 10.7 & 17 & 34.0 & 10 & 17.5 & 19 & 30.6 & 0.06 \\
\hline Other & 10 & 17.9 & 4 & 8.0 & 6 & 10.5 & 7 & 11.3 & \\
\hline \multicolumn{10}{|l|}{ Comorbidities $^{\mathrm{a}}$} \\
\hline Cardiovascular disease & 36 & 64.3 & 33 & 66.0 & 38 & 66.7 & 44 & 71.0 & 0.88 \\
\hline Cerebrovascular disease & 4 & 7.1 & 3 & 6.0 & 5 & 8.8 & 5 & 8.1 & 0.97 \\
\hline Peripheral vascular disease & 13 & 23.2 & 7 & 14.0 & 11 & 19.3 & 14 & 22.6 & 0.63 \\
\hline Diabetes mellitus & 27 & 48.2 & 29 & 58.0 & 32 & 56.1 & 32 & 51.6 & 0.74 \\
\hline Respiratory disease & 16 & 28.6 & 10 & 20.0 & 9 & 15.8 & 14 & 22.6 & 0.43 \\
\hline cancer (other than skin cancer) & 8 & 14.3 & 11 & 22.0 & 8 & 14.0 & 11 & 17.7 & 0.67 \\
\hline Musculoskeletal & 18 & 32.1 & 14 & 28.0 & 14 & 24.6 & 22 & 35.5 & 0.60 \\
\hline Other & 36 & 64.3 & 30 & 60.0 & 37 & 64.9 & 37 & 59.7 & 0.91 \\
\hline \multicolumn{10}{|l|}{ Comorbidity count } \\
\hline 0 to 2 & 24 & 42.9 & 23 & 46.0 & 29 & 50.9 & 28 & 45.2 & \\
\hline 3 to 6 & 32 & 57.1 & 27 & 54.0 & 28 & 49.1 & 34 & 54.8 & 0.85 \\
\hline \multicolumn{10}{|l|}{ Cause of ESKD } \\
\hline Glomerulonephritis & 8 & 14.3 & 9 & 18.0 & 7 & 12.3 & 14 & 22.6 & \\
\hline Hypertension & 10 & 17.9 & 7 & 14.0 & 12 & 21.1 & 9 & 14.5 & \\
\hline Polycystic kidney & 2 & 3.6 & 1 & 2.0 & 4 & 7.0 & 5 & 8.1 & \\
\hline Diabetes mellitus & 20 & 35.7 & 22 & 44.0 & 27 & 47.4 & 23 & 37.1 & 0.55 \\
\hline Other & 16 & 28.6 & 11 & 22.0 & 7 & 12.3 & 11 & 17.7 & \\
\hline
\end{tabular}

${ }^{a}$ multiple comorbidities possible

likely to undertake haemodialysis when compared to the peritoneal dialysis or predialysis population.

Table 4 presents self-reported HR-QOL, disability and personal well-being measures at baseline. With the exception of dialysis location on EQ-5D-3 L VAS, these self-reported scales of health and disability were not impacted by being on dialysis or by dialysis modality, location or duration.

\section{Discussion}

The DOS65 study is an accelerated prospective cohort longitudinal design study over 3 years, designed to obtain HRQoL data, which when linked to clinical data, will help inform clinicians' and patients' shared decision-making with respect to end stage kidney disease (ESKD), outcomes and options for management in New Zealand (NZ) [2]. The outcomes of this study align well with the SONG initiative, and the importance of reporting patient-related outcomes [1]. This paper reports the baseline characteristics of the study cohort.

Patients who participated in the study were more likely (than those who declined to participate) to be male, of NZ European descent and on dialysis treatment. However, despite this, by selecting 3 different regions with 
Table 3 Sociodemographic characteristics of study cohort by type of treatment, location and time on treatment

\begin{tabular}{|c|c|c|c|c|c|c|c|c|c|c|c|}
\hline \multirow[b]{2}{*}{ Characteristic } & \multirow{2}{*}{$\begin{array}{l}\text { Not on dialysis } \\
(\mathrm{N}=56)\end{array}$} & \multicolumn{3}{|l|}{ Type of dialysis } & \multicolumn{3}{|c|}{ Dialysis Location** } & \multicolumn{4}{|c|}{ Time on dialysis** } \\
\hline & & $\begin{array}{l}\text { Haemodialysis } \\
(n=109)\end{array}$ & $\begin{array}{l}\text { Peritoneal } \\
(n=60)\end{array}$ & $p$ value * & $\begin{array}{l}\text { Home } \\
(n=70)\end{array}$ & $\begin{array}{l}\text { In centre } \\
(n=99)\end{array}$ & $p$ value ${ }^{*}$ & $\begin{array}{l}\text { Incident } \\
(<1 \text { year }) \\
(n=50)\end{array}$ & $\begin{array}{l}\text { Prevalent } \\
(1-3 \text { years }) \\
(n=57)\end{array}$ & $\begin{array}{l}\text { Prevalent } \\
(>3 \text { years }) \\
(n=62)\end{array}$ & $p$ value * \\
\hline \multicolumn{12}{|l|}{ Gender } \\
\hline Male & 37 & 63 & 44 & 0.045 & 53 & 54 & 0.005 & 33 & 35 & 39 & 0.883 \\
\hline Female & 19 & 46 & 16 & & 17 & 45 & & 17 & 22 & 23 & \\
\hline \multicolumn{12}{|l|}{ Age group } \\
\hline $65-69$ & 20 & 43 & 24 & & 29 & 38 & & 20 & 21 & 26 & \\
\hline $70-74$ & 11 & 35 & 18 & 0.729 & 22 & 31 & 0.808 & 16 & 15 & 22 & 0.262 \\
\hline $75-79$ & 13 & 22 & 10 & & 11 & 21 & & 6 & 16 & 10 & \\
\hline$\geq 80$ & 12 & 9 & 8 & & 8 & 9 & & 8 & 5 & 4 & \\
\hline \multicolumn{12}{|l|}{ Prioritised ethnicity } \\
\hline European & 30 & 32 & 34 & & 40 & 26 & & 19 & 23 & 24 & \\
\hline Māori & 10 & 31 & 9 & 0.005 & 10 & 30 & 0.000 & 10 & 18 & 12 & 0.457 \\
\hline Pacific & 6 & 35 & 11 & & 11 & 35 & & 17 & 10 & 19 & \\
\hline Other & 10 & 11 & 6 & & 9 & 8 & & 4 & 6 & 7 & \\
\hline \multicolumn{12}{|c|}{ Distance in $\mathrm{km}$ to dialysis centre } \\
\hline Less than 10 & 30 & 65 & 27 & & 29 & 63 & & 28 & 31 & 33 & \\
\hline $10-49$ & 19 & 39 & 23 & 0.019 & 26 & 36 & 0.000 & 16 & 23 & 23 & 0.739 \\
\hline $50+$ & 7 & 5 & 10 & & 15 & 0 & & 6 & 3 & 6 & \\
\hline \multicolumn{12}{|l|}{ Lifestyle behaviour } \\
\hline Current smoker & 4 & 7 & 3 & 0.708 & 4 & 6 & 1.000 & 2 & 2 & 6 & 0.287 \\
\hline $\begin{array}{l}\text { Currently drinks } \\
\text { alcohol }\end{array}$ & 30 & 39 & 27 & 0.240 & 38 & 28 & 0.001 & 19 & 22 & 25 & 0.965 \\
\hline Lives alone & 16 & 10 & 7 & 0.606 & 7 & 10 & 1.000 & 2 & 6 & 9 & 0.182 \\
\hline \multicolumn{12}{|l|}{ Own home } \\
\hline Yes & 37 & 57 & 43 & 0.040 & 51 & 49 & 0.008 & 31 & 35 & 34 & 0.505 \\
\hline No & 19 & 51 & 17 & & 19 & 49 & & 18 & 22 & 28 & \\
\hline Missing & 0 & 1 & 0 & & 0 & 1 & & 1 & 0 & 0 & \\
\hline \multicolumn{12}{|c|}{ Pension is the only source of income } \\
\hline Yes & 35 & 80 & 40 & 0.309 & 45 & 75 & 0.083 & 32 & 44 & 44 & 0.400 \\
\hline No & 21 & 28 & 20 & & 25 & 23 & & 17 & 13 & 18 & \\
\hline Missing & 0 & 1 & 0 & & 0 & 1 & & 1 & 0 & 0 & \\
\hline \multicolumn{12}{|c|}{ Have a community services card? } \\
\hline Yes & 43 & 85 & 42 & 0.505 & 44 & 83 & 0.007 & 34 & 44 & 49 & 0.210 \\
\hline No & 13 & 23 & 17 & & 25 & 15 & & 14 & 13 & 13 & \\
\hline Missing & 0 & 1 & 1 & & 1 & 1 & & 2 & 0 & 0 & \\
\hline \multicolumn{12}{|l|}{ Standard of living } \\
\hline Fairly Low/Low & 4 & 15 & 2 & 0.033 & 3 & 14 & 0.034 & 5 & 5 & 7 & 0.901 \\
\hline $\begin{array}{l}\text { High/fairly high/ } \\
\text { medium }\end{array}$ & 52 & 93 & 58 & & 67 & 84 & & 44 & 52 & 55 & \\
\hline Missing & 0 & 1 & 0 & & 0 & 1 & & 1 & 0 & 0 & \\
\hline \multicolumn{12}{|c|}{ Adequacy of income for daily needs } \\
\hline $\begin{array}{l}\text { Enough/More } \\
\text { than enough }\end{array}$ & 27 & 50 & 26 & 0.712 & 31 & 45 & 0.834 & 21 & 30 & 25 & 0.373 \\
\hline $\begin{array}{l}\text { Not enough/Just } \\
\text { enough }\end{array}$ & 29 & 58 & 34 & & 39 & 53 & & 28 & 27 & 37 & \\
\hline Missing & 0 & 1 & 0 & & 0 & 1 & & 1 & 0 & 0 & \\
\hline
\end{tabular}


Table 3 Sociodemographic characteristics of study cohort by type of treatment, location and time on treatment (Continued)

\begin{tabular}{|c|c|c|c|c|c|c|c|c|c|c|c|}
\hline \multirow[b]{2}{*}{ Characteristic } & \multirow{2}{*}{$\begin{array}{l}\text { Not on dialysis } \\
(\mathrm{N}=56)\end{array}$} & \multicolumn{3}{|l|}{ Type of dialysis } & \multicolumn{3}{|c|}{ Dialysis Location** } & \multicolumn{4}{|c|}{ Time on dialysis** } \\
\hline & & $\begin{array}{l}\text { Haemodialysis } \\
(n=109)\end{array}$ & $\begin{array}{l}\text { Peritoneal } \\
(n=60)\end{array}$ & $p$ value * & $\begin{array}{l}\text { Home } \\
(n=70)\end{array}$ & $\begin{array}{l}\text { In centre } \\
(n=99)\end{array}$ & $p$ value * & $\begin{array}{l}\text { Incident } \\
(<1 \text { year }) \\
(n=50)\end{array}$ & $\begin{array}{l}\text { Prevalent } \\
(1-3 \text { years) } \\
(n=57)\end{array}$ & $\begin{array}{l}\text { Prevalent } \\
(>3 \text { years }) \\
(n=62)\end{array}$ & $p$ value * \\
\hline Qualifications & 26 & 56 & 26 & 0.217 & 31 & 51 & 0.233 & 24 & 27 & 31 & 0.850 \\
\hline None & 30 & 49 & 34 & & 39 & 44 & & 25 & 30 & 28 & \\
\hline $\begin{array}{l}\text { Secondary school/ } \\
\text { higher/trade } \\
\text { qualification }\end{array}$ & 0 & 4 & 0 & & 0 & 4 & & 1 & 0 & 3 & \\
\hline \multicolumn{12}{|l|}{ Missing } \\
\hline \multicolumn{12}{|l|}{ Comorbidity Count } \\
\hline $0-2$ & 24 & 52 & 28 & 0.900 & 32 & 48 & 0.722 & 23 & 29 & 28 & 0.802 \\
\hline $3+$ & 32 & 57 & 32 & & 38 & 51 & & 27 & 28 & 34 & \\
\hline $\begin{array}{l}\text { NZDep score } \\
\text { (mean \& SD) }\end{array}$ & $6.6(2.9)$ & $7.3(2.8)$ & $6.2(3.1)$ & 0.016 & $6.1(2.9)$ & $7.6(2.8)$ & 0.001 & $7.0(3.1)$ & $6.9(2.9)$ & $6.9(2.9)$ & 0.98 \\
\hline
\end{tabular}

${ }^{*} P$ values are from chi-square test except for NZDep score where $P$ values are from ANOVA. Non-dialysis group now excluded from test when comparing dialysis types, ** 8 people are in 'in training' for dialysis. Two of them were included in "home" group as they are training at home, other 6 were included in "centre" group

differing population characteristics, we achieved a reasonable representation of the NZ dialysis population in this age group. Given the much higher incidence and prevalence of ESKD (3.5-5.5 fold) [18] and CKD [19] among Māori and Pacific populations, and differences in outcome measures and HRQoL by ethnicity [20-23], it was essential that good representation of these populations was achieved.

While diabetes mellitus was the most common cause of ESKD this was less prevalent than in the general NZ dialysis population [4]. As one would expect, this is a highly comorbid population. When compared to the DOPPS population over 65 , comorbidity rates were broadly similar [24], with more than half the study populations having cardiac disease. This population had a higher rate of diabetes mellitus but lower rates of cerebrovascular and peripheral vascular disease. The increased prevalence of diabetes mellitus reflects the participation of Māori and Pacific people with well documented increased propensity to ESKD as a result of diabetes mellitus [18].

In the general population socioeconomic deprivation plays an important role in the development and progression of kidney disease, and conversely, chronic kidney disease may result in socioeconomic deprivation $[20,25,26]$. Study participants were much more likely to live in a more deprived area, were less well educated, and were financially less well off than other New Zealanders of a similar age. While the association of socioeconomic disadvantage and renal replacement therapy is well established in the general population, Australian data has previously suggested that this is less relevant in older dialysis patients [27]. To our knowledge this is the first cohort to describe an association between socioeconomic disadvantage and renal replacement therapy in this population. The main factor influencing where participants resided and hence deprivation index was ethnicity. Māori and Pacific people were much more likely to live in the two most socioeconomically deprived deciles with $68 \%$ of Māori and $81 \%$ of Pacific participants living in decile 9 or 10 areas as opposed to $13 \%$ of NZ Europeans.

New Zealand has among the highest rates of home-based dialysis internationally, even among older age groups. [4]. In this cohort, $42 \%$ were dialysing at home which reflects the national trend [4]. Most patients dialysing at home were on $\mathrm{PD}$, with only 10 participants on home HD. We found that patients dialysing at home were more likely to own their own home, more likely to have more than one source of income, less likely to have a community services card, and lived in less deprived areas but interestingly were just as likely to report inadequate or barely adequate financial resources. Those patients on home dialysis were also more likely to be male, be of NZ European descent and to live further from the dialysis centre. The pre-dialysis population was similar to the peritoneal dialysis population with similar apparent socioeconomic advantage over the in-centre dialysis population. While the population undertaking in-centre haemodialysis was different than the home or pre-dialysis population, dialysis vintage was associated with no significant demographic differences.

Despite the differences in socioeconomic status, multiple measures of health and disability status did not vary by being on dialysis, by dialysis modality, dialysis location of time on renal replacement therapy. This would imply that factors outside of socioeconomic status have more influence on these characteristics.

Strengths of this study are that we achieved good representation of the NZ dialysis population over the age of 65 . Importantly, participation of Māori and Pacific people 


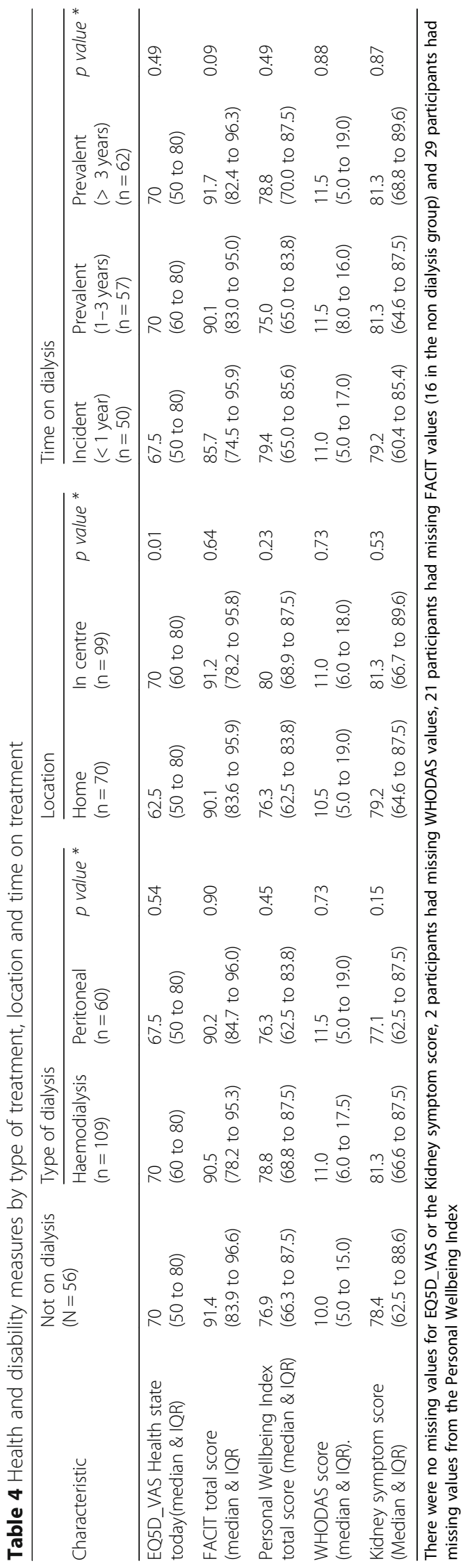


were at rates higher, or equivalent to, rates of renal replacement therapy in these ethnic groups. Comorbidity data was individually collected from patient hospital records. Multiple measures of socioeconomic status were collected either directly from the participant or from national census data. Prioritised ethnicity data was collected directly from the participant which has been shown to be more reliable than electronic health records [6]. Multiple measures of health status, HRQoL, disability and personal well-being were recorded by trained interviewers.

In NZ dialysis is entirely provided within the publiclyfunded health system and therefore decisions related to acceptance onto dialysis, the modality of dialysis, and subsequent participation in this study, is not subject to participant insurance status or other financial factors.

While those who participated were representative of the NZ wide dialysis population of a similar age, females, Māori and Pacific people and those not on dialysis were less likely to participate. In particular, a relatively low number of Māori and Pacific who were either undertaking peritoneal dialysis or who were pre-dialysis participated. This may limit the generalisability of findings for these populations, though as a prospective cohort study, participation bias has little concern when looking at risk factors for outcomes of interest that have not yet occurred.

Our future analyses will concentrate on characterizing the evolution of patient-related over time. Our study has an accelerated longitudinal design, which is similar to that used in the Dialysis Outcomes and Practice Patterns Study, where analyses are also made on a mix of incident and prevalent dialysis patients [3]. The difference is that in the DOPPS, most analyses are performed using time-to-event models for outcomes such as mortality. As such, patients are "lined up" at their time of study entry, controlling for vintage (on a continuous scale) by including it in a model. In our study, most analyses will be observations of patient-related outcomes at various follow-up points post-dialysis inception. As such, patients will be "lined up" by vintage. For these sorts of outcomes, there is no difference between the accelerated longitudinal design used in our study versus that which using an incident or inception cohort design - in our study, prevalent patients recruited at year 2 post-dialysis inception followed for two years with have the same cross-sectional characteristics at each landmark as incident patients recruited at dialysis inception followed for four years. In both cases, there is no issue with survival bias; for instance, one can only compare HRQoL at a landmark in patients who have survived to that point, and no other analytical framework makes clinical sense. Table 2 demonstrates that patients can be pooled without any sub-cohort effect related the sampling frame.

In the case that we analyse follow-up data using time-to-event models, for instance to assess mortality, we will use similar methods to the DOPPS [3] with left truncation (at time of study entry) in to account for the potential bias of missing patients who did not make it to the point of study entry. In such analyses, survival time is conditional on having already survived from the point of risk (dialysis inception) to first coming under observation (study entry). In New Zealand, less than $2 \%$ of the dialysis population aged 65 or older receive a renal transplant (4), and the competing risk of transplant will not be a factor in analysing outcomes in this study.

\section{Conclusions}

In summary, we report the baseline characteristics of participants enrolled prospectively into a longitudinal cohort observation study examining HRQoL factors with clinical characteristics on dialysis outcomes in a group of New Zealand aged 65 years or older who are either on dialysis or have been educated about dialysis [2]. In combination with our protocol paper [2], this paper allows readers a clear understanding of the participants enrolled in the study, in order to compare with their own clinical practice. Subsequent publications are planned, analysing the prospective longitudinal data to identify key factors that determine both outcome and quality of life for individuals of this age group.

\section{Abbreviations}

ANOVA: Analysis of variance; ANZDATA: Australian and New Zealand Dialysis and Transplantation Registry; CKD: Chronic kidney disease; CVD: Cardiovascular disease; DHB: District Health Board; DOPPS: Dialysis outcomes and practice patterns study; DOS65: Dialysis outcomes in those aged 65 years or older study; eGFR: estimated glomerular filtration rate; EQ5D-3 L: EuroQual questionnaire; ESKD: End stage kidney disease; FACIT: Functional assessment of chronic illness therapy; HRQoL: Health related quality of life; IQR: Interquartile range; KDQoL - 36: Kidney disease quality of life 36 questionnaire; NZ: New Zealand; NZDep: New Zealand deprivation index; SONG: Standardised outcomes in Nephrology

\section{Acknowledgements}

We thank the patients for participating in this project and our team of interviewers. We would also like to acknowledge the late Professor John Campbell for his role in the study design.

\section{Funding}

This research was funded by The Health Research Council of New Zealand (10/354) and they had no input into the study or analyses.

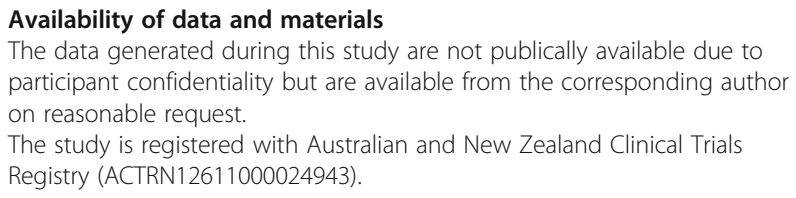

Authors' contributions

Research idea and study design: RW, SD, MM, SW, JS, AH. Data acquisition BM, SW, AS MM, AH, JS, RW. Statistical Analysis AS. Data analysis and interpretation: SD, RW, JS, AS, SW, MM. Preparation of manuscript: BM, SD, JS, MM, AS, SW, AH, RW. Each author contributed important intellectual content during manuscript drafting or revision and accepts accountability for the overall work by ensuring that questions pertaining to the accuracy or integrity of any portion of the work are appropriately investigated and resolved. All authors have read and approved the final version of the manuscript for publication. 


\section{Ethics approval and consent to participate}

Ethical approval was granted by the New Zealand Health and Disability Ethics Committee (MEC/10/08/084) All participants gave written informed consent. Consent for publication not required.

\section{Competing interests}

The authors have no competing interests.

\section{Publisher's Note}

Springer Nature remains neutral with regard to jurisdictional claims in published maps and institutional affiliations.

\section{Author details}

${ }^{1}$ Department of Preventive and Social Medicine, University of Otago, PO Box 56, Dunedin 9054, New Zealand. ${ }^{2}$ Department of Medicine, University of Otago, Dunedin, New Zealand. ${ }^{3}$ Department of Renal Medicine, Middlemore Hospital, Counties Manukau District Health Board, Manukau, New Zealand. ${ }^{4}$ Renal Medicine, Hamilton Hospital, Waikato District Health Board, Hamilton, New Zealand. ${ }^{5}$ Biostatistics unit, University of Otago, Dunedin, New Zealand.

\section{Received: 23 September 2018 Accepted: 3 April 2019}

Published online: 23 April 2019

\section{References}

1. Tong A, Manns M, Hemmelgarn B, et al. Establishing Core outcome domains in hemodialysis: report of the standardized outcomes in Nephrology- hemodialysis (SONG-HD) consensus workshop. Am J Kidney Dis. 2016;69(1):97-107.

2. Walker R, Derrett S, Campbell J, Marshall MR, Henderson A, Schollum J, et al. Dialysis outcomes in those aged $>65$ years. BMC Nephrol. 2013;14:175.

3. Pisoni RL, Giliespie BW, Dickinson DM, et al. The Dialysis outcomes and practice patterns study (DOPPS): design, data elements and methodology. Am J Kid Dis. 2004;44(1):7-15.

4. ANZDATA Registry Report. In: McDonald S, Excell L, Livingston B, editors. Australia and New Zealand Dialysis and Transplant Registry Adelaide, South Australia; 2015

5. Statistics New Zealand. Statistical Standard for Ethnicity. In: Wellington Statistics New Zealand; 2005.

6. Page $M$, Wyeth $E$, Samaranayaka A, et al. Accuracy of ethnicity data recorded in clinical records and the New Zealand Dialysis and transplant registry. NZ Med J. 2017;130:1454

7. Ministry of Social Development - work and income. New Zealand superannuation (http://www.workandincome.govt.nz/products/a-z-benefits/ nz-superannuation.htm|\#null). Accessed 17 May 2016

8. Work and Income New Zealand. https://www.workandincome.govt.nz/ products/a-z-benefits/community-services-card.html. Accessed 21 Aug 2015.

9. Statistics New Zealand. NZ Stat 2001 census: People. http://nzdotstat.stats. govt.nz/wbos/index.aspx. Accessed 21 Aug 2015.

10. C S, Crampton P, King P, Waldegrave C. NZiDep: a New Zealand index of socioeconomic deprivation for individuals. Soc Sci Med. 2006;62(6):1474-85.

11. van Reenan M, Oppe M. EQ-5D-3L User Guide: Basic information on how to use the EQ-5D-3L instrument. Version 5.1. 2015. Rotterdam, The Netherlands: EuroQol Research Foundation.

12. Hays RD, Kallich JD, Mapes DL, Coons SJ, Carter WB. Development of the kidney disease quality of life (KDQOL) instrument. Qual Life Res. 1994;3(5): 329-38

13. Lowrie C. Every Wednesday at 10:30: community building in a suburban dialysis clinic. Dialysis and Transplantation. 2003;32(4):206-11.

14. LowieEG CRB, LePain N, Schatell D. Medical outcomes study short form-36: a consistent and powerful predictor of morbidity and mortality in dialysis patients. Am J Kidney Dis. 2003;41(6):1286-92.

15. Webster K, Cella D, Yost K. The functional assessment of chronic illness therapy (FACIT) measurement sustem: properties, applications, and interpretation. Health Qual Life Outcomes. 2003;1:79.

16. Üstün TB, Kostanjsek N, Chatterij S, Rehm J. Manual for WHO Disability Assessment Schedule (WHODAS 2.0). Malta: WHO Press; 2010.

17. International Wellbeing Group. Personal Wellbeing Index. Melbourne: Australian Centre on Quality of Life, Deakin University; 2006.

18. Collins JF. Kidney disease in Maori and Pacific people in New Zealand. Clin Nephrol. 2010;74(Suppl 1):S61-5.
19. Lloyd H, Li G, Tomlin A, Tilyard MW, Walker R, Schollum J. The prevalence and risk factors for chronic kidney disease in primary health Care in the Southern Region of New Zealand. Nephrology (2018) online.

20. Mapes DL, Bragg-Gresham JL, Bommer J, et al. Health-related quality of life in the Dialysis outcomes and practice patterns study (DOPPS). Am J Kidney Dis. 2004:44(5 Suppl 2):54-60.

21. Mowatt G, Vale L, Perez J, et al. Systematic review of the effectiveness and cost-effectiveness, and economic evaluation, of home versus hospital or satellite unit haemodialysis for people with end-stage renal failure. Health Technol Assess. 2003;7(2):1-174.

22. Jolly SE, Burrows NR, Chen SC, Li S, Jurkovitz CT, Norris KC, et al. Racial and ethnic differences in mortality among individuals with chronic kidney disease: results from the kidney early evaluation program (KEEP). Clin J Am Soc Nephrol. 2011;6(8):1858-65.

23. Lopes AA, Bragg-Gresham JL, Satayathum S, McCullough K, Pifer T, Goodkin DA, et al. Health-related quality of life and associated outcomes among hemodialysis patients of different ethnicities in the United States: the Dialysis outcomes and practice patterns study (DOPPS). Am J Kidney Dis. 2003:41(3):605-15.

24. Canaud B, Tong $L$, Tentori $F$, et al. Clinical practices and outcomes in elderly hemodialysis patients: results from the Dialysis outcomes and practice patterns study (DOPPS). Clin J Am Soc Nephrology. 2011:67(7):1651-2.

25. Plantinga LC. Socio-economic impact in CKD. Nephrologie et Therapeutique. 2013;9(1):1-7.

26. Fored CM, Ejerblad E, Fryzek JP, et al. Socio-economic status and chronic renal failure: a population-based case-control study in Sweden. Nephrol Dial Transplant. 2003;18(1):82-8

27. Grace BS, Clayton P, Cass A, McDonald SP. Socio-economic status and incidence of renal replacement therapy: a registry study of Australian patients. Nephrol Dial Transpl. 2012;27(11):4713-80.

Ready to submit your research? Choose BMC and benefit from:

- fast, convenient online submission

- thorough peer review by experienced researchers in your field

- rapid publication on acceptance

- support for research data, including large and complex data types

- gold Open Access which fosters wider collaboration and increased citations

- maximum visibility for your research: over $100 \mathrm{M}$ website views per year

At BMC, research is always in progress.

Learn more biomedcentral.com/submissions 